\title{
A facile one-step synthesis of prussian blue/polyaniline/graphene oxide nanocomposites for electrochemical sensing of hydrogen
}

\author{
peroxide \\ Ziyin Yang, Xiaohui Zheng and Jianbin Zheng * \\ Institute of Analytical Science, Shaanxi Provincial Key Laboratory of Electroanalytical Chemistry, \\ Northwest University, Xi’an, Shaanxi 710069, China. E-mail address: zhengjb@nwu.edu.cn
}

\begin{abstract}
Prussian blue/polyaniline/graphene oxide (PB/PANI/GO) nanocomposites were synthesized and used for electrochemical sensing of hydrogen peroxide $\left(\mathrm{H}_{2} \mathrm{O}_{2}\right)$. PB/PANI/GO nanocomposites were synthesized through a facile one-step approach, where aniline acted as both the precursor of PANI and the reductant for $\mathrm{FeCl}_{3}-\mathrm{K}_{3}\left[\mathrm{Fe}(\mathrm{CN})_{6}\right]$, therefore making polymerization of aniline and anchoring of $\mathrm{PB}$ nanoparticles on PANI/GO occur simultaneously. Then, the nanocomposites were characterized by transmission electron microscopy (TEM), X-ray diffraction spectroscopy (XRD), fourier transform infrared spectroscopy (FTIR) and electrochemical techniques. The results indicated that PB nanoparticles with the size of about $4.0 \mathrm{~nm}$ were homogeneously distributed on the surface of PANI/GO, which made the sensor based on PB/PANI/GO exhibit an excellent performance toward $\mathrm{H}_{2} \mathrm{O}_{2}$ detection with a wide linear range of $5.0 \mu \mathrm{M}$ to $1.275 \mathrm{mM}$, a sensitivity of 60.16 $\mu \mathrm{A} \mathrm{mM} \mathrm{m}^{-1} \mathrm{~cm}^{-2}$ and a low detection limit of $1.9 \mu \mathrm{M}(\mathrm{S} / \mathrm{N}=3)$.
\end{abstract}

Keywords: Prussian blue; Polyaniline; Graphene oxide; Hydrogen peroxide; Nonenzymatic sensor

\section{Introduction}

The accurate determination of hydrogen peroxide $\left(\mathrm{H}_{2} \mathrm{O}_{2}\right)$ is important for its wide applications $[1,2]$. Up to now, many methods were developed to detect $\mathrm{H}_{2} \mathrm{O}_{2}$ [3-6]. In particular, electrochemistry sensors which based on the simple and low cost electrode were extensively studied [7]. Moreover, in order to improve the catalytic activity of sensors for $\mathrm{H}_{2} \mathrm{O}_{2}$ oxidation/reduction, various nanomaterials were employed to modify electrodes due to their large specific surface areas as well as 
unique electronic and catalytic properties [8-11]. Among nanomaterials, prussian blue (PB) aroused growing interest because of its excellent electrocatalytic activity toward $\mathrm{H}_{2} \mathrm{O}_{2}$ electroreduction [12, 13]. In addition, $\mathrm{H}_{2} \mathrm{O}_{2}$ sensors based on $\mathrm{PB}$ usually required a low working potential [14], which was beneficial to prevent the interference of other substances. However, the poor stability and low conductivity of PB limited its extensive applications [15]. Recently, it has been reported that hybrid nanomaterial might endow the integrity with enhanced activity compared with single component [16]. Therefore, in order to improve stability, conductivity and catalytic activity of $\mathrm{PB}$, it was desirable to disperse $\mathrm{PB}$ on supporting materials with excellent electrical conductivity, large surface area and high stability.

Graphene oxide (GO) was two-dimensional and one-atom-thick sheet material, which exhibited interesting features of large surface area and good stability. PB/GO nanocomposites were investigated [17,18]. Zhang [17] synthesized GO/PB hybrid film by electropolymerizing PB onto the GO modified glassy carbon electrode and then used for electrochemical sensing applications. Li [18] prepared PB/graphene composite film and employed the composite for electrochemical sensing of $\mathrm{H}_{2} \mathrm{O}_{2}$. Compared with PB films and graphene sheets, PB/graphene composite film showed the largest current response to the reduction of $\mathrm{H}_{2} \mathrm{O}_{2}$ due to the synergistic effects between graphene sheets and PB nanoparticles. In addition, polyaniline (PANI) was conductive polymer with excellent electronic properties [19]. Meanwhile, both GO and PANI were functionalized by many groups and these groups can be employed as the anchor sites for nanoparticles, which prevented nanoparticles from aggregating $[20,21]$. Therefore, the combination of GO with PANI made GO/PANI an advanced support material with excellent electrical conductivity, large surface area and high stability. Up to now, a few examples of synthesis of GO/PANI-based nanocomposites were demonstrated [22, 23], where GO/PANI were synthesized first by electrochemical or chemical oxidative polymerization method, then nanoparticles are anchored on the surface of GO/PANI. However, the synthesis of GO/PANI-based nanocomposites was complicated. Meanwhile, as far as we know, few studies have managed to support PB on GO/PANI. Therefore, it is still highly necessary to develop 
a facile one-step approach to synthesize PB/PANI/GO for the determination of $\mathrm{H}_{2} \mathrm{O}_{2}$.

In this paper, PB/PANI/GO nanocomposites were synthesized through spontaneous polymerization of aniline and formation of $\mathrm{PB}$ nanoparticles on PANI/GO, where aniline was employed as both the precursor of PANI and the reductant for $\mathrm{FeCl}_{3}-\mathrm{K}_{3}\left[\mathrm{Fe}(\mathrm{CN})_{6}\right]$. Then, the non-enzymatic $\mathrm{H}_{2} \mathrm{O}_{2}$ sensor based on $\mathrm{PB} / \mathrm{PANI} / \mathrm{GO}$ was fabricated and electrochemical performance of the sensor toward $\mathrm{H}_{2} \mathrm{O}_{2}$ was investigated.

\section{Experimental}

\subsection{Reagents and materials}

Aniline $\left(\mathrm{C}_{6} \mathrm{H}_{7} \mathrm{~N}, 99.9 \%\right)$ and ferric chloride crystal $\left(\mathrm{FeCl}_{3} \cdot 6 \mathrm{H}_{2} \mathrm{O}, 99.0 \%\right)$ were purchased from Xi'an Chemical Reagent (Xi'an, China). Graphite powder (99.998\%, 325 mesh, Alfa Aesar) and $\mathrm{H}_{2} \mathrm{O}_{2}(30 \% \mathrm{v} / \mathrm{v}$ solution) were obtained from Shanghai Yuanju Biotechnology Co., Ltd (Shanghai, China).

\subsection{Apparatus}

Transmission electron microscopic (TEM) images were carried out by Tecnai $\mathrm{G}^{2}$ F20 S-TWIN (FEI, USA). X ray diffraction (XRD) patterns of the samples were taken by D/MAX 3C (Rigaku, Japan). Fourier transform infrared spectroscopy (FTIR) was recorded with TENSIR 27 (Bruker, German). Electrochemical measurements were carried out in a conventional three-electrode electroanalysis system controlled by $\mathrm{CHI}$ 660 electrochemical workstation (Shanghai CH Instrument Co. Ltd., China). A conventional three-electrode cell was used, including a glassy carbon electrode (GCE, geometric area $=0.07 \mathrm{~cm}^{2}$ ) as the working electrode, a saturated calomel electrode as the reference electrode and platinum foil as the counter electrode. All potentials given in this work were referred to the saturated calomel electrode.

\subsection{Synthesis of PB/PANI/GO}

GO was synthesized from graphite powder [24]. $100 \mu \mathrm{L}$ of aniline was added in aqueous solution of GO $(50 \mathrm{~mL}, 0.5 \mathrm{mg} / \mathrm{mL})$ under vigorous stirring for $30 \mathrm{~min}$. Then, $1 \mathrm{~mL}$ of $12 \mathrm{M} \mathrm{HCl}$ (containing $0.012 \mathrm{~g} \mathrm{FeCl}_{3} \cdot 6 \mathrm{H}_{2} \mathrm{O}$ and $0.014 \mathrm{~g} \mathrm{~K}_{3}\left[\mathrm{Fe}(\mathrm{CN})_{6}\right]$ ) was slowly added into above solution and the solution was stirred for $24 \mathrm{~h}$. After that, the product was separated from solution by centrifugation and was washed for three times 
by doubly distilled water.

\subsection{Electrode modification}

GCE was prepared by the casting method. $2.0 \mathrm{mg}$ of PB/PANI/GO were dispersed into $1 \mathrm{~mL}$ of water and the solution was sonicated for 8 minutes. After that, $6 \mu \mathrm{L}$ of PB/PANI/GO solution and $3 \mu \mathrm{L}$ of Nafion (0.05 wt $\%$ ) was dropped on the surface of GCE and then dried at room temperature in air.

\section{Results and Discussion}

\subsection{Characterizations of PB/PANI/GO}

Figure 1 showed the schematic illustration for the preparation of PB/PANI/GO. PB/PANI/GO were synthesized through spontaneous polymerization of aniline and formation of PB nanoparticles using aniline as both the precursor of PANI and the reductant for $\mathrm{FeCl}_{3}-\mathrm{K}_{3}\left[\mathrm{Fe}(\mathrm{CN})_{6}\right]$. When adding aniline into $\mathrm{GO}$ solution, aniline was adsorbed on the surface of GO through hydrogen bond force [25], which was beneficial for the subsequent polymerization of aniline on the surface of GO. In addition, it was reported that $\mathrm{FeCl}_{3}-\mathrm{K}_{3}\left[\mathrm{Fe}(\mathrm{CN})_{6}\right]$ was strong oxidant in acidic solution. Therefore, after adding acidic $\mathrm{FeCl}_{3}-\mathrm{K}_{3}\left[\mathrm{Fe}(\mathrm{CN})_{6}\right]$ into above solution, aniline was polymerized on the surface of $\mathrm{GO}$, meanwhile, $\mathrm{Fe}^{3+}$ was reduced to $\mathrm{Fe}^{2+}$ by aniline and then $\mathrm{PB}$ nanoparticles was obtained through the reaction of $\mathrm{Fe}^{2+}$ with $\left[\mathrm{Fe}(\mathrm{CN})_{6}\right]^{3-}$. Therefore, PB/PANI/GO were synthesized through a facile one-step approach using aniline as both the precursor of PANI and the reductant for $\mathrm{FeCl}_{3}-\mathrm{K}_{3}\left[\mathrm{Fe}(\mathrm{CN})_{6}\right]$.

The morphologies of $\mathrm{GO}$ and $\mathrm{PB} / \mathrm{PANI} / \mathrm{GO}$ were characterized by TEM. As shown in Figure 2 (A), GO revealed nanosheet structures with wrinkles and folds. In the case of PB/PANI/GO, from Figure 2 (B) and (C), it can be seen that a large number of nanoparticles with the size of about $4.0 \mathrm{~nm}$ were homogeneously distributed on the surface of PANI/GO, which benefited from the nucleation sites provided by the functional groups on the surface of PANI/GO. These functional groups prevented PB nanoparticles from aggregating and facilitated the homogeneous distribution. Furthermore, the chemical structural characterization of PB/PANI/GO was investigated by XRD. As shown in Figure 1 (D), PB/PANI/GO revealed some peaks at $24.8^{\circ}, 35.4^{\circ}, 43.6^{\circ}, 54.2^{\circ}$ and $57.3^{\circ}$, which were indexed to (220), (400), 
(422), (600) and (620) planes of PB [26], therefore confirming that the nanoparticles decorated on PANI/GO were PB.

FTIR spectra (Figure 3) was employed to study the chemical structural characterizations of GO and PB/PANI/GO. It can be seen that GO (curve a) showed absorption peaks at $3417 \mathrm{~cm}^{-1}, 1734 \mathrm{~cm}^{-1}, 1627 \mathrm{~cm}^{-1}$ and $1065 \mathrm{~cm}^{-1}$ which can be assigned to $-\mathrm{OH}, \mathrm{C}=\mathrm{O}, \mathrm{C}=\mathrm{C}, \mathrm{C}-\mathrm{O}$ stretching, respectively [27]. In the case of $\mathrm{PB} / \mathrm{PANI} / \mathrm{GO}$ (curve b), the new peaks at 1137 , and $1340 \mathrm{~cm}^{-1}$ were ascribed to $\mathrm{C}=\mathrm{N}$ stretching vibration and $\mathrm{C}-\mathrm{N}$ vibrations of PANI [28]. Moreover, comparing with the spectra of GO, PB/PANI/GO also showed two new peak at $2084 \mathrm{~cm}^{-1}$ and $498 \mathrm{~cm}^{-1}$ due to the stretching modes of $\mathrm{C} \equiv \mathrm{N}$ group and the formation of $\mathrm{Fe}^{\mathrm{II}}-\mathrm{CN}-\mathrm{Fe}^{\mathrm{III}}[15]$, which confirmed the presence of PB. Therefore, on the basis of the results of TEM, XRD and FTIR characterizations, GO and PB/PANI/GO nanocomposites were successfully prepared.

\subsection{Electrochemical properties of PB/PANI/GO nanocomposites}

Cyclic voltammograms (CVs) were recorded to investigate the electrocatalytic behavior of $\mathrm{PB} / \mathrm{PANI} / \mathrm{GO} / \mathrm{GCE}$. Figure 4 (A) showed $\mathrm{CVs}$ obtained at $\mathrm{PB} / \mathrm{PANI} / \mathrm{GO} / \mathrm{GCE}$ in $0.5 \mathrm{M} \mathrm{KCl}$ solution $(\mathrm{HCl}, \mathrm{pH} 3.0)$ at a scan rate of $100 \mathrm{mV} / \mathrm{s}$. From Figure 4 (A), it can be seen that PB/PANI/GO/GCE exhibited a pair of well-defined redox peaks with a formal redox potential of $184 \mathrm{mV}$, which were due to the transitions between PB and Prussian white $\left(\mathrm{K}_{2} \mathrm{Fe}^{\mathrm{II}}\left[\mathrm{Fe}^{\mathrm{II}}(\mathrm{CN})_{6}\right]\right)$ [29]. Moreover, the potential separation of the redox peaks was $19 \mathrm{mV}$ and the potential separation was very close to the theoretical value, indicating that fast charge transfer occurred in PB/PANI/GO composite [18]. The electrochemical stability of PB/PANI/GO/GCE was studied. As shown in Figure 4 (B), no significant current decreased after thirty cycles, indicating the good stability. Furthermore, in order to examined the possible kinetic mechanism of PB/PANI/GO/GCE, the effect of scan rates on the current response was investigated (Figure $4(\mathrm{C}$ and $\mathrm{D})$ ). It can be seen that the current increased in a linear relationship with the square root of scan rates, implying a diffusion controlled process [30]. The diffusion-controlled process was due to that the redox transition of $\mathrm{PB}$ was companied with the transfer of $\mathrm{K}^{+}$and therefore the 
difussion of $\mathrm{K}^{+}$might control the electrochemical process and result in the linear dependence of the peak current on the square root of scan rate [31, 32].

CVs were also employed to study the electrocatalytic behavior of modified electrodes toward $\mathrm{H}_{2} \mathrm{O}_{2}$. Figure 5 showed $\mathrm{CVs}$ obtained at bare GCE (a, b), GO/GCE (c, d) and PB/PANI/GO/GCE (e, f) in 0.5 M 0.5 M KCl solution $(\mathrm{HCl}, \mathrm{pH} 3.0)$ in the absence (a, c, e) and presence (b, d, f) of $1.0 \mathrm{mM} \mathrm{H}_{2} \mathrm{O}_{2}$ at the scan rate of $60 \mathrm{mV} / \mathrm{s}$. As shown in Figure 5 (A), in the absence (a, c) or presence (b, d) of $1.0 \mathrm{mM} \mathrm{H}_{2} \mathrm{O}_{2}$, both bare GCE and GO/GCE exhibit almost no electrochemical response. However, it can be seen from Figure 5 (B) that PB/PANI/GO/GCE showed a pair of well-defined redox peaks (curve e) in the absence of $\mathrm{H}_{2} \mathrm{O}_{2}$. Moreover, the cathodic peak current increased and the anodic peak current decreased (curve f) after adding $\mathrm{H}_{2} \mathrm{O}_{2}$, indicating the electrocatalytic reduction of $\mathrm{H}_{2} \mathrm{O}_{2}$. During electrocatalytic reduction of $\mathrm{H}_{2} \mathrm{O}_{2}$, PB acted as an electron transfer mediator as follows [33]:

$$
\begin{gathered}
2 \mathrm{~K}_{2} \mathrm{Fe}^{\mathrm{II}}\left[\mathrm{Fe}^{\mathrm{II}}(\mathrm{CN})_{6}\right]+\mathrm{H}_{2} \mathrm{O}_{2} \rightarrow 2 \mathrm{KFe}^{\mathrm{III}}\left[\mathrm{Fe}^{\mathrm{II}}(\mathrm{CN})_{6}\right]+2 \mathrm{OH}^{-}+2 \mathrm{~K}^{+} \\
\mathrm{KFe}^{\mathrm{III}}\left[\mathrm{Fe}^{\mathrm{II}}(\mathrm{CN})_{6}\right]+\mathrm{e}^{-}+\mathrm{K}^{+} \rightarrow \mathrm{K}_{2} \mathrm{Fe}^{\mathrm{II}}\left[\mathrm{Fe}^{\mathrm{II}}(\mathrm{CN})_{6}\right]
\end{gathered}
$$

In order to study the sensing property of $\mathrm{PB} / \mathrm{PANI} / \mathrm{GO} / \mathrm{GCE}$, the amperometric current-time curve was recorded. Figure 6 (A) displayed the amperometric current-time curve obtained by PB/PANI/GO/GCE with successive addition of varying $\mathrm{H}_{2} \mathrm{O}_{2}$ concentrations in $0.5 \mathrm{M} \mathrm{KCl}$ solution $(\mathrm{HCl}, \mathrm{pH} 3.0)$ at $0 \mathrm{~V}$. It was clear that the reduction current increased after adding $\mathrm{H}_{2} \mathrm{O}_{2}$ into $0.5 \mathrm{M} \mathrm{KCl}$ solution $(\mathrm{HCl}$, $\mathrm{pH}$ 3.0). The calibration curve of PB/PANI/GO/GCE was shown in Figure 6 (B). The linear regression equation was expressed as $\mathrm{Ip}(\mu \mathrm{A})=0.2351+4.211 \cdot \mathrm{C}(\mathrm{mM})$. The linear range was estimated to be from $5.0 \mu \mathrm{M}$ to $1.275 \mathrm{mM}(\mathrm{R}=0.998)$. The sensitivity was calculated using the equation $\mathrm{S}=\mathrm{b} / \mathrm{A}$, where $\mathrm{b}$ was the the slope of the analytical curve and A was the geometric area of glassy carbon electrode. Therefore, the sensitivity was estimated to be $60.16 \mu \mathrm{A} \mathrm{mM}^{-1} \mathrm{~cm}^{-2}$. The detection limit was 1.9 $\mu \mathrm{M}$ at a signal-to-noise ratio of 3. As shown in Table1, PB/PANI/GO exhibited an excellent performance for hydrogen peroxide analysis. Therefore, PANI/GO with excellent electrical conductivity, large surface area, high stability and a large number of functional groups can act as the support for nucleation and growth of highly 
dispersed PB. PB combined with PANI/GO improved the stability and conductivity of $\mathrm{PB}$, therefore increasing the catalytic activity for $\mathrm{H}_{2} \mathrm{O}_{2}$ reduction.

Furthermore, in order to study the selectivity of PB/PANI/GO/GCE, the amperometric current-time curve was recorded. Figure 7 showed the amperometric current-time curve obtained at PB/PANI/GO/GCE with successive addition of $\mathrm{H}_{2} \mathrm{O}_{2}$, glucose (Glu), ascorbic acid (AA) and L-cysteine (L-cys). As shown in Figure 7, Glu, AA and L-cys produced almost no current response, indicating a good selectivity. Moreover, $\mathrm{PB} / \mathrm{PANI} / \mathrm{GO} / \mathrm{GCE}$ retained almost $88 \%$ of its initial current response after fifteen days and the relative standard deviation was about $7.1 \%$ for six PB/PANI/GO/GCE, confirming the favorable long-term stability and good reproducibility.

\section{Conclusion}

Prussian blue/polyaniline/graphene oxide (PB/PANI/GO) nanocomposites were successfully synthesized through a facile one-step approach. The experimental results revealed that the spontaneous redox reactions between aniline and $\mathrm{FeCl}_{3}-\mathrm{K}_{3}\left[\mathrm{Fe}(\mathrm{CN})_{6}\right]$ made the preparation method simple without employing additional reducing agents, surface modifier or complicated steps. Meanwhile, large numbers of PB with a narrow size distribution were well distributed on the surface of PANI/GO, which not only enhanced the electron transfer and improved catalytic activity but also also provided more catalytic surface for $\mathrm{H}_{2} \mathrm{O}_{2}$ reaction, therefore making PB/PANI/GO exhibit an excellent performance for hydrogen peroxide analysis. Considering the facile preparation route and excellent experimental results, this synthetic concept may paved the way for the facial synthesis of other $\mathrm{GO} /$ conductive polymer-based nanocomposites for applications.

\section{Acknowledgments}

The authors gratefully acknowledge the financial support of this project by the National Science Foundation of China (21575113, 21275116 and 21105080), Specialized Research Fund for the Doctoral Program of Higher Education (No. 20126101120023), the Natural Science Foundation of Shaanxi Province in China (2013KJXX-25), and the Scientific Research Foundation of Shaanxi Provincial Key 
Laboratory (13JS097, 13JS098, 14JS094, 15JS100). 


\section{References:}

[1] Tsiafoulis CG, Trikalitis PN, Prodromidis MI (2005) Electrochemistry communications 7:1398-1404.

[2] Nossol E, Zarbin AJG (2009) Advanced Functional Materials 19:3980-3986.

[3] Matos RC, Coelho EO (2006) Talanta 69:1208-1214.

[4] King DW, Cooper WJ, Rusak SA (2007) Analytical chemistry 79:4169-4176.

[5] Srikun D, Albers AE, Nam CI (2010) Journal of the American Chemical Society 132:4455-4465.

[6] Zhang C, Li L, Ju J (2016) Electrochimica Acta 210:181-189.

[7] Uzunoglu A, Song S, Stanciu LA (2016) Journal of The Electrochemical Society $163: 379-384$.

[8] Wang T, Zhu H, Zhuo J (2013) Analytical chemistry 85:10289-10295.

[10] Ren S, Wang H, Zhang Y (2016) Analyst 141:2741-2747.

[11] Lou X, Zhu C, Pan H (2016) Electrochimica Acta 205:70-76.

[12] Su L, Xiong Y, Yang H (2016) Journal of Materials Chemistry B 4:128-134.

[13] Prabhu P, Babu RS, Narayanan SS (2014) Journal of Solid State Electrochemistry 18:883-891.

[14] Michopoulos A, Kouloumpis A, Gournis D (2014) Electrochimica Acta $146: 477-484$.

[15] Tuo X, Li B, Chen C (2016) Synthetic Metals 213:73-77.

[16] Liu Z, Zhao B, Shi Y (2010) Talanta 81:1650-1654.

[17] Zhang Y, Sun X, Zhu L (2011) Electrochimica Acta 56:1239-1245.

[18] Li SJ, Du JM, Shi YF (2012) Journal of Solid State Electrochemistry $16: 2235-2241$.

[19] Liang B, Qin Z, Zhao J (2014) Journal of Materials Chemistry A 2:2129-2135.

[20] Qin Y, Li J, Kong Y (2014) Nanoscale 6:1281-1285.

[21] Feng X, Zhang Y, Yan Z (2014) Journal of Solid State Electrochemistry 18: $1717-1723$.

[22] Han G, Liu Y, Zhang L (2014) Scientific reports 4:4824--4831.

[23] Hu XW, Mao CJ, Song JM (2013) Biosensors and Bioelectronics 41:372-378. 
[24] Perera SD, Mariano RG, Vu K (2012) Acs Catalysis 2:949-956.

[25] Tong Z, Yang Y, Wang J (2014) Journal of Materials Chemistry A 2:4642-4651.

[26] Gong H, Sun M, Fan R (2013) Microchimica Acta 180:295-301.

[27] Kim NH, Kuila T, Lee JH (2013) Journal of Materials Chemistry A 1:1349-1358.

[28] Ma R, Wang M, Dam DT (2015) ChemElectroChem 2:503-507.

[29] Zeng J, Wei W, Liu X (2008) Microchimica Acta 160:261-267.

[30] Wang L, Ye Y, Lu X (2013) Electrochimica Acta 114:223-232.

[31] Michopoulos A, Kouloumpis A, Gournis D (2014) Electrochimica Acta $146: 477-484$.

[32] Zhu N, Han S, Gan S (2013) Advanced Functional Materials 23:5297-5306.

[33] Yang JH, Myoung N, Hong HG (2012) Electrochimica Acta 81:37-43.

[34] Wang L, Zhu H, Hou H (2012) Journal of Solid State Electrochemistry 16:1693-1700.

[35] Li SJ, Du JM, Shi YF (2012) Journal of Solid State Electrochemistry $16: 2235-2241$.

[36] Meng F, Yan X, Liu J (2011) Electrochimica Acta 56:4657-4662.

[37] Li Y, Liu X, Zeng X (2009) Microchimica Acta 165:393-398.

[38] Jiang Y, Zhang X, Shan C (2011) Talanta 85:76-81. 


\section{Figure Caption}

Figure 1. Experimental procedure of synthesis of PB/PANI/GO.

Figure 2. TEM images of nanocomposites: (A) GO, (B, C) PB/PANI/GO and XRD of (D) PB/PANI/GO.

Figure 3. FTIR spectra of (a) GO and (b) PB/PANI/GO nanocomposites.

Figure 4. (A) Cyclic voltammograms obtained by $\mathrm{PB} / \mathrm{PANI} / \mathrm{GO} / \mathrm{GCE}$ in $0.5 \mathrm{M} \mathrm{KCl}$ solution $(\mathrm{HCl}$, $\mathrm{pH}$ 3.0) at a scan rate of $100 \mathrm{mV} / \mathrm{s}$. (B) Cyclic voltammograms obtained by PB/PANI/GO/GCE in $0.5 \mathrm{M} \mathrm{KCl}$ solution $(\mathrm{HCl}, \mathrm{pH}$ 3.0) after thirty cycles at a scan rate of $100 \mathrm{mV} / \mathrm{s}$. (C) Cyclic voltammograms obtained by $\mathrm{PB} / \mathrm{PANI} / \mathrm{GO} / \mathrm{GCE}$ in $0.5 \mathrm{M} \mathrm{KCl}$ solution $(\mathrm{HCl}, \mathrm{pH} 3.0)$ at different scan rates (from a to g: 20, 40, 60, 80, 100, 120 and $140 \mathrm{mV} / \mathrm{s}$ ). (D) Linear fitting program of current versus the square root of scan rate.

Figure 5. Cyclic voltammograms obtained by bare GCE (a, b) GO/GCE (c, d) and $\mathrm{PB} / \mathrm{PANI} / \mathrm{GO} / \mathrm{GCE}(\mathrm{e}, \mathrm{f})$ in $0.5 \mathrm{M} \mathrm{KCl}$ solution $(\mathrm{HCl}, \mathrm{pH} 3.0)$ in the absence (a, c, e) and presence (b, d, f) of $1.0 \mathrm{mM} \mathrm{H}_{2} \mathrm{O}_{2}$ at a scan rate of $60 \mathrm{mV} / \mathrm{s}$.

Figure 6. (A) Amperometric curve obtained by PB/PANI/GO/GCE for successive additions of $\mathrm{H}_{2} \mathrm{O}_{2}$ in $0.5 \mathrm{M} \mathrm{KCl}$ solution ( $\mathrm{HCl}, \mathrm{pH} 3.0$ ) at the work potential of $0 \mathrm{~V}$ under constant stirring. (B) Calibration curve of $\mathrm{H}_{2} \mathrm{O}_{2}$ versus its concentration.

Figure 7. Amperometric response of $0.05 \mathrm{mM} \mathrm{H}_{2} \mathrm{O}_{2}$, glucose, ascorbic acid and L-cysteine on $\mathrm{PB} / \mathrm{PANI} / \mathrm{GO} / \mathrm{GCE}$ in $0.5 \mathrm{M} \mathrm{KCl}$ solution $(\mathrm{HCl}, \mathrm{pH} 3.0)$ at the work potential of $0 \mathrm{~V}$ under constant stirring. 


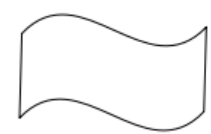

Aniline
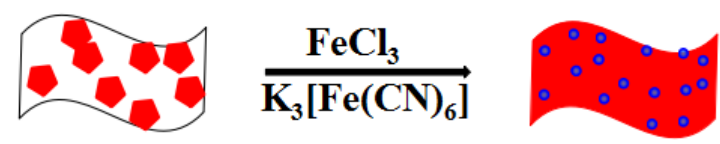

Jgo Aniline PANI $\bigcirc$ PB

Figure 1 

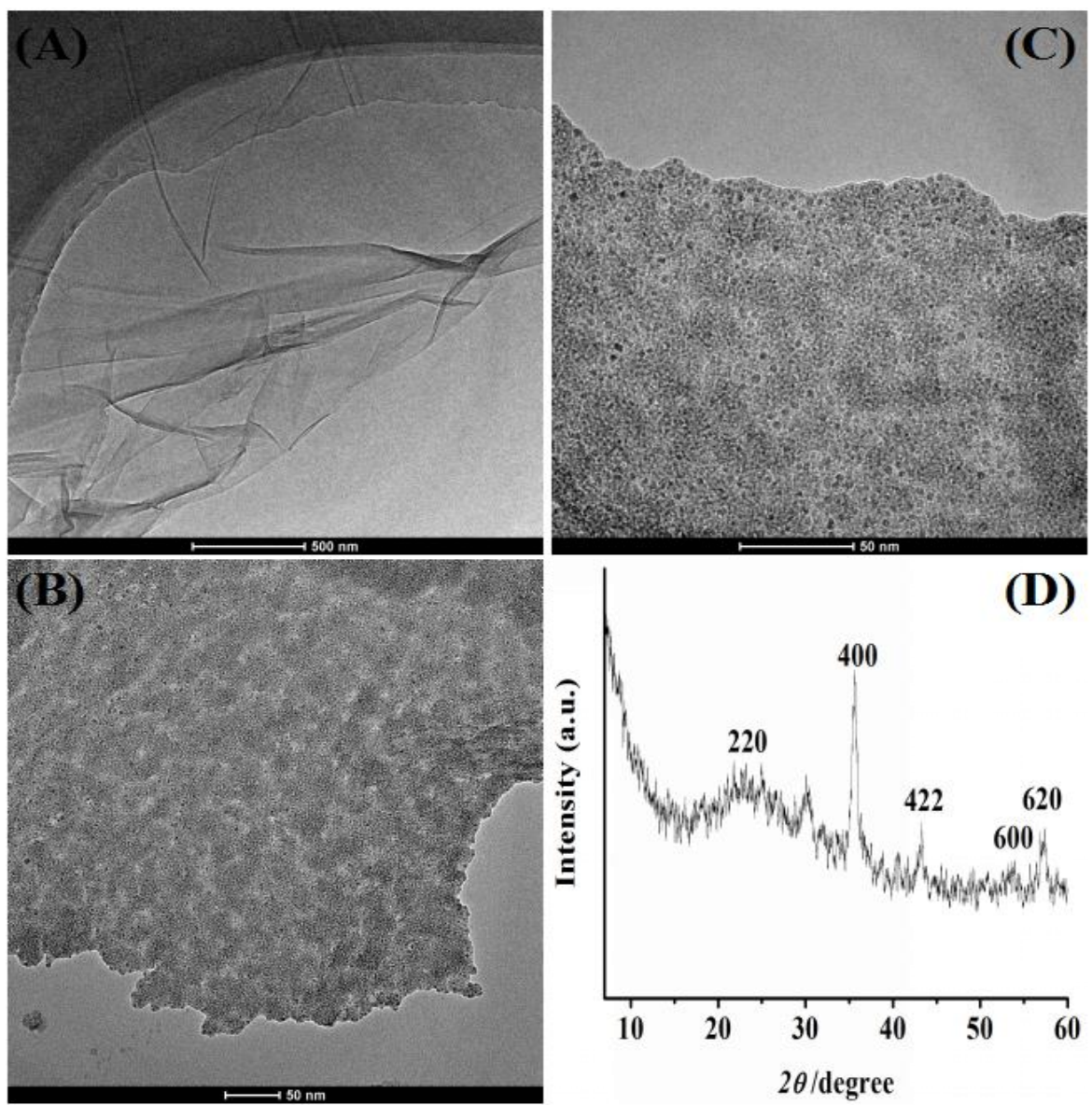

Figure 2 


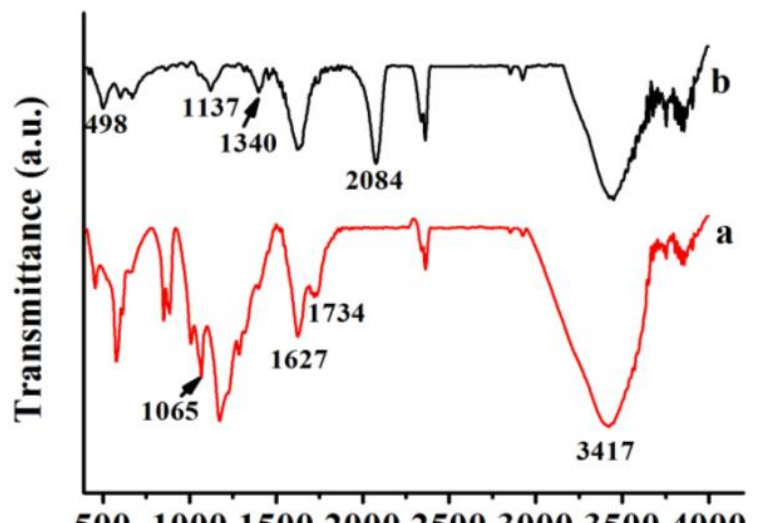

5001000150020002500300035004000

Wavenumber $\left(\mathrm{cm}^{-1}\right)$

Figure 3 

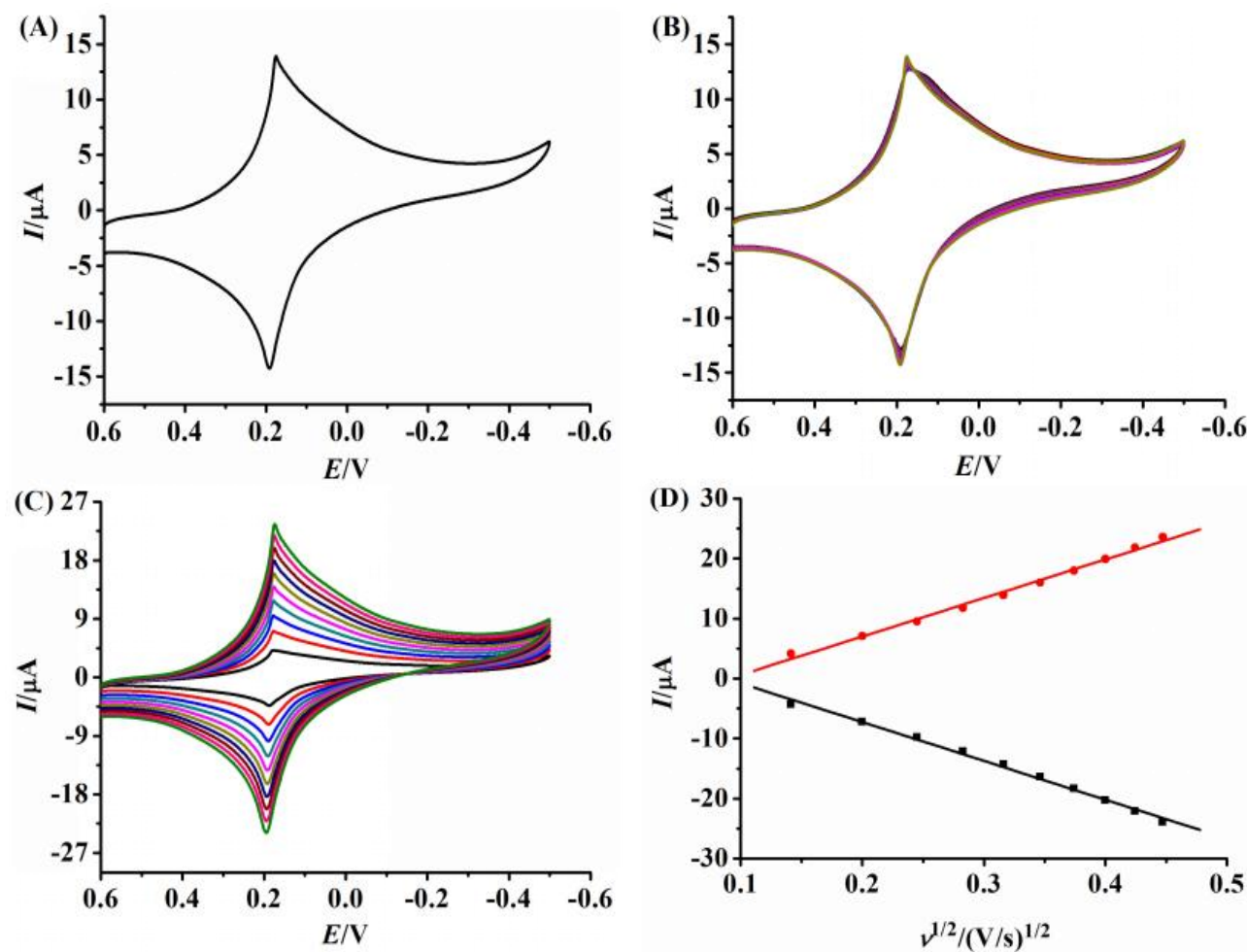

Figure 4 

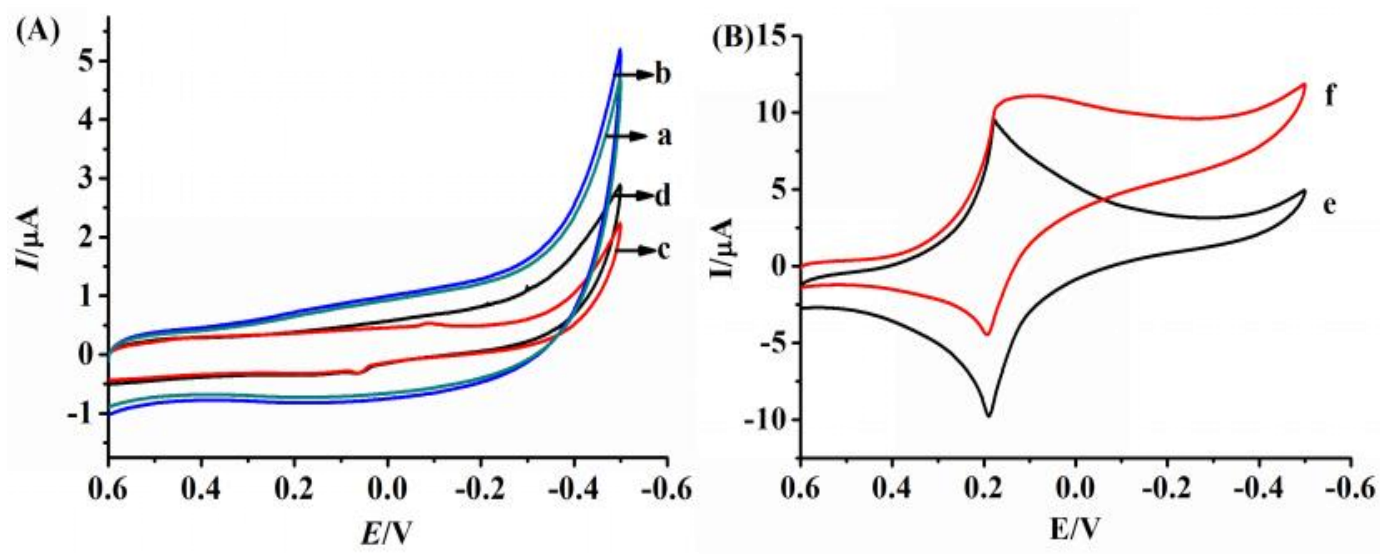

Figure 5 

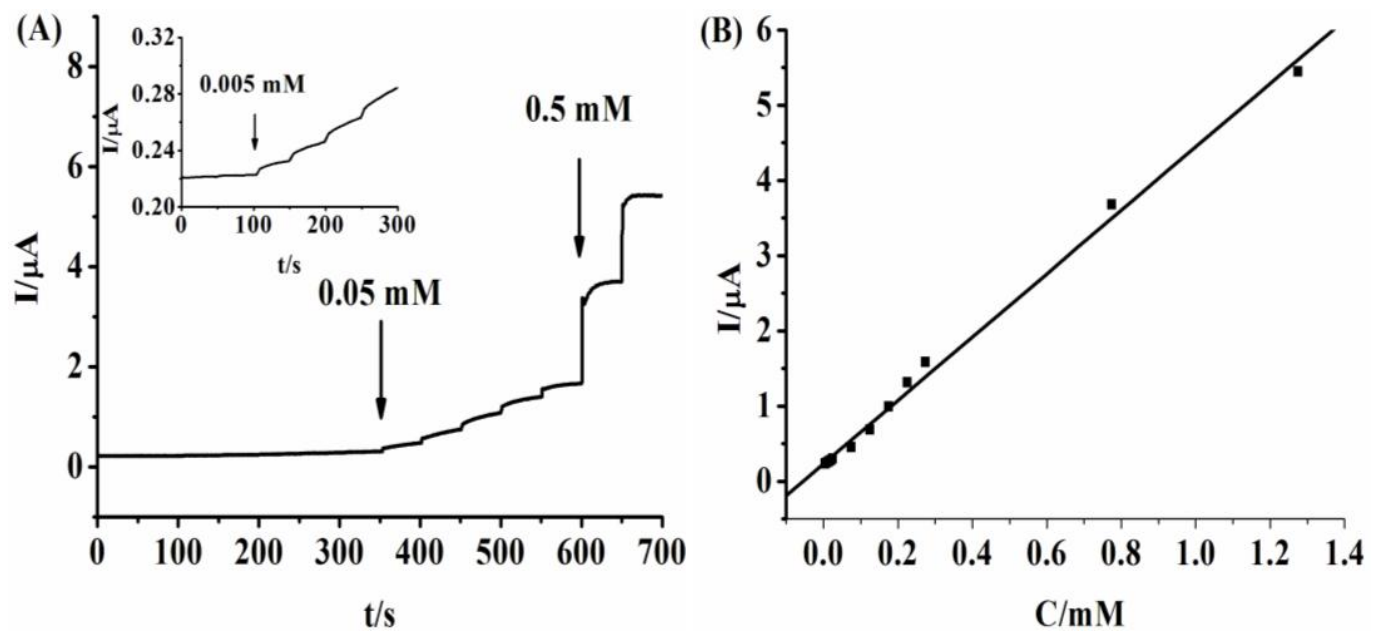

Figure 6 


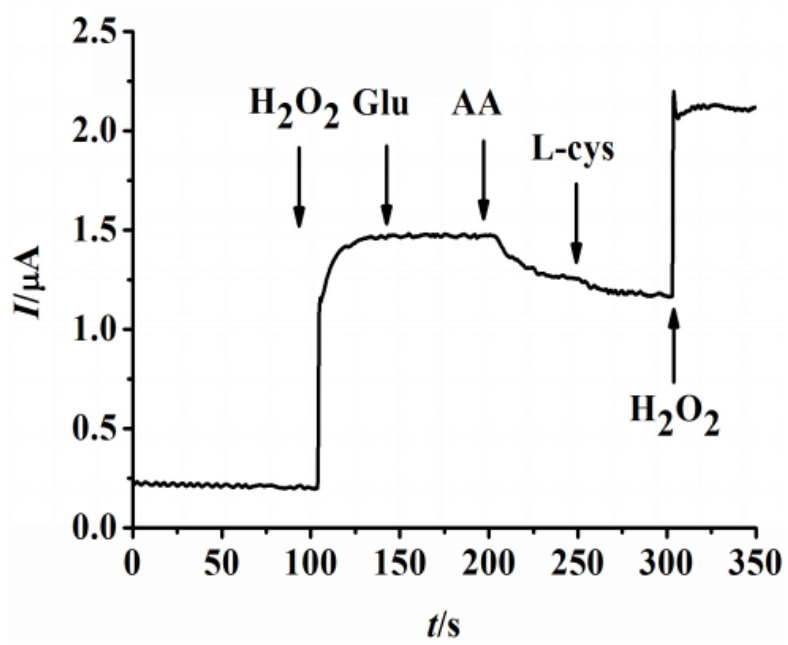

Figure 7 
Table 1. Comparison of non-enzymatic $\mathrm{H}_{2} \mathrm{O}_{2}$ sensors.

\begin{tabular}{ccccc}
\hline \multirow{2}{*}{ Sensors } & $\begin{array}{c}\text { Applied } \\
\text { Potential } \\
(\mathrm{V})\end{array}$ & $\begin{array}{c}\text { Linear range } \\
(\mathrm{mM})\end{array}$ & $\begin{array}{c}\text { Detection } \\
\text { limit }(\mu \mathrm{M})\end{array}$ & References \\
& 0.1 & $0.005-1.2$ & 0.122 & 17 \\
GO/PB & -0.2 & $0.05-5$ & 0.02 & 18 \\
PB-graphene & -0.4 & $0.006-18$ & 0.7 & 34 \\
AgNPs/GO-CHIT/cysteamine/Au & -0.2 & $0.005-5$ & 0.02 & 35 \\
AuNPs/graphite & -0.4 & $0.01-8$ & 3.26 & 36 \\
Nanoporous gold & -0.1 & $0.05-6$ & 1 & 37 \\
PB/CILE & 0.35 & $0.01-3$ & 7 & 38 \\
PB-graphene & 0 & $0.005-1.275$ & 1.9 & This work \\
PB/PANI/GO & & & & \\
\hline
\end{tabular}

